\title{
Adaptação de cultivares de soja irrigada em solos arenosos
}

\author{
Adaptation of irrigated soy cultivars in sandy soils \\ Adaptación de cultivares de soja de regadío en suelos arenosos
}

Recebido: 21/01/2021 | Revisado: 22/01/2021 | Aceito: 25/01/2021 | Publicado: 31/01/2021

Kessiley Aparecido Rodrigues

ORCID: https://orcid.org/0000-0002-8103-3538

Universidade Federal do Mato Grosso do Sul, Brasil

E-mail: kessileyrodrigues@gmail.com

Ricardo Gava

ORCID: https://orcid.org/0000-0001-6268-5728 Universidade Federal do Mato Grosso do Sul, Brasil E-mail: ricardo.gava@ufms.br

Mayara Fávero Cotrim

ORCID: https://orcid.org/0000-0003-0878-4922 Universidade Estadual Paulista, Brasil

E-mail: mayaracotrim5@gmail.com

Leonardo Bezerra da Silva

ORCID: https://orcid.org/0000-0001-7902-7537

Universidade Federal do Mato Grosso do Sul, Brasil E-mail: leobesilva@gmail.com

Adriano da Silva Lopes

ORCID: https://orcid.org/0000-0003-2211-6576 Universidade Estadual de Mato Grosso do Sul, Brasil E-mail: lopes@uems.br

Maiane Rodrigues do Nascimento ORCID: https://orcid.org/0000-0002-4170-5694

Universidade Federal do Maranhão, Brasil

E-mail: maianerodrigues707@gmail.com

Plinio Antonio Guerra Filho

ORCID: https://orcid.org/0000-0002-1590-5123

Universidade Federal do Maranhão, Brasil E-mail: plinio.guerra@ufma.br

Job Teixeira de Oliveira

ORCID: https://orcid.org/0000-0001-9046-0382 Universidade Federal do Mato Grosso do Sul, Brasil E-mail: job.oliveira@hotmail.com

\begin{abstract}
Resumo
Com a irrigação os produtores podem explorar áreas antes não agricultáveis, e maximizar a sua produtividade. Com a hipótese de adaptação de cultivares de soja em condições sub-ótimas de água no solo, objetivou-se avaliar as diferentes variedades de soja (Glycine max (L.)) em solos arenosos em condição de sequeiro e irrigado. O delineamento utilizado foi o de blocos Casualizados em esquema de faixas constituídas pelas cultivares DM 80 I79 IPRO, BONUS IPRO, Maracaí IPRO, DM 75I76, Foco IPRO e Aporé IPRO sob duas condições de água no solo (sequeiro e irrigado) com 4 repetições por tratamento, totalizando 48 parcelas avaliadas. Foram analisadas altura de plantas, altura de inserção vagem, número de plantas, número de vagens por planta, número de grãos por planta e número de ramos e número de nós, massa de cem grãos e produtividade de grãos. Em solos arenosos, a variedade DM 80179 IPRO quando submetida a irrigação apresenta incremento na produtividade. Quando as cultivares foram submetidas à irrigação, todas expressaram incremento na produtividade, fato este comprovado pela não diferenciação estatística entre cultivares, conseguindo equilibrar seu potencial produtivo, variando somente devido a características de resistência a déficit hídrico, causando variabilidade produtiva entre as mesmas.
\end{abstract}

Palavras-chave: Produtividade; Glycine max; Déficit hídrico.

\section{Abstract}

With irrigation, producers can explore areas that were previously not arable, and maximize their productivity. With the hypothesis of adaptation of soybean cultivars in sub-optimal conditions of water in the soil, the objective was to evaluate the different varieties of soybean (Glycine max (L.)) in sandy soils under dry and irrigated conditions. The design used was the Randomized blocks in a strip scheme consisting of the cultivars DM 80179 IPRO, BONUS IPRO, Maracaí IPRO, DM 75I76, Foco IPRO and Aporé IPRO under two conditions of water in the soil (dry and irrigated) with 4 repetitions per treatment, totaling 48 evaluated plots. Plant height, pod insertion height, number of plants, number of 
pods per plant, number of grains per plant and number of branches and number of nodes, mass of one hundred grains and grain yield were analyzed. In sandy soils, the DM 80 I79 IPRO variety, when subjected to irrigation, shows an increase in productivity. When the cultivars were subjected to irrigation, all expressed an increase in productivity, a fact proven by the non-statistical differentiation between cultivars, managing to balance their productive potential, varying only due to characteristics of resistance to water deficit, causing productive variability between them.

Keywords: Productivity; Glycine max; Water deficit.

\section{Resumen}

Con el riego, los productores pueden explorar áreas que antes no eran cultivables y maximizar su productividad. Con la hipótesis de adaptación de cultivares de soja en condiciones subóptimas de agua en el suelo, el objetivo fue evaluar las diferentes variedades de soja (Glycine $\max ($ L.)) en suelos arenosos en condiciones secas e irrigadas. El diseño utilizado fue el de Bloques Aleatorizados en esquema de franjas conformado por los cultivares DM 80I79 IPRO, BONUS IPRO, Maracaí IPRO, DM 75I76, Foco IPRO y Aporé IPRO en dos condiciones de agua en el suelo (seco y regado) con 4 repeticiones por tratamiento, totalizando 48 parcelas evaluadas. Se analizaron altura de planta, altura de inserción de vaina, número de plantas, número de vainas por planta, número de granos por planta y número de ramas y número de nudos, masa de cien granos y rendimiento de grano. En suelos arenosos, la variedad DM 80I79 IPRO, cuando se somete a riego, muestra un aumento de productividad. Cuando los cultivares fueron sometidos a riego, todos expresaron un incremento en la productividad, hecho evidenciado por la no diferenciación estadística entre cultivares, logrando equilibrar su potencial productivo, variando solo por características de resistencia al déficit hídrico, provocando variabilidad productiva entre ellos.

Palabras clave: Productividad; Glycine max; Déficit hídrico.

\section{Introdução}

A produção agrícola brasileira engloba muitas atividades agrícolas, sendo que no Brasil se destaca o plantio de soja. Segundo o boletim de grãos da Companhia Nacional de Abastecimento (CONAB 2020), a área plantada da soja brasileira cresceu $3 \%$ em relação à safra passada, saindo de 35.874 mil hectares para os atuais 36.949 mil hectares. Esse comportamento encontrou respaldo na forte liquidez que o produto apresentou na comercialização, no comportamento do câmbio e à expectativa futura para a oleaginosa. A produção nesta temporada atingiu 120.936,4 mil toneladas, representando aumento de 5,1\% em relação ao período anterior (CONAB 2020).

O complexo soja tornou-se, no Brasil e no mundo, imprescindível no agronegócio, devido a sua gama de utilizações na alimentação humana e animal, assim como em vários processos industriais com grande importância para a economia. Tal importância também está ligada ao alto potencial produtivo da cultura.

O suprimento adequado de água durante todo o ciclo da cultura é fator preponderante para se atingir altas produtividades, como mostra o trabalho de Flumignan et al. (2015) que estudaram a necessidade de irrigação complementar da soja na região sul de Mato Grosso do Sul, através da simulação de 11 safras de soja utilizando os dados climáticos históricos de 2001 à 2013, e concluíram que houve necessidade de complementação com irrigação para atender à demanda de água da soja durante o seu ciclo, mesmo em safras com quantidade e distribuição de chuvas adequadas.

A preocupação dos múltiplos usos da água tem uma recomendação estratégica, buscando planejamento territorial, exigindo uma ação integrada dos diversos setores, que visam a utilização desses usos, entre eles: consumo humano e produção de energia. $\mathrm{O}$ tratamento mais adequado das questões que abrangem o uso da água para projetos de irrigação, como a aquisição de outorgas e a concorrência com outros usos, necessita de atenção para ações acordantes dos envolvidos para uma melhor aplicação dos recursos hídricos. (Rodrigues, 2020).

Culturas irrigadas tendem a apresentar um potencial de desenvolvimento melhor, e a irrigação suplementaria no período chuvoso, pode alavancar a produtividade da soja, fazendo com que seja maximizada a eficiência do uso da água. Essa estratégia minimiza o conflito pelo uso da água por diferentes setores da sociedade, principalmente no decorrer do período seco, em que licenças para uso de água para irrigação podem ser liberadas apenas no período de maior disponibilidade, reduzindo o cultivo no período seco do ano. (Silva et al., 2020). 
Mesmo em regiões com alta precipitação pluviométrica, podem ocorrer falta de chuvas em períodos específicos do ciclo, fazendo com que áreas irrigadas tornem-se importantes para garantir a produtividade esperada (Gava, 2014). Diante do exposto, este trabalho tem como objetivo, avaliar as diferentes variedades de soja (Glycine max (L.)), em solos arenosos em condição de sequeiro e irrigação, tendo como hipótese, a adaptação de cultivares de soja em condições sub-ótimas de água no solo.

\section{Material e Métodos}

A pesquisa foi realizada na Fazenda Santo Antônio localizada no município de Paraíso das Águas - MS, localizando se na latitude $18^{\circ} 58^{\prime} 49.87^{\prime \prime}$ Sul e longitude $52^{\circ} 55^{\prime}$ '09.56' 'Oeste, com uma altitude de 675 metros. O clima da região é definido como tropical com estação seca (Aw) segundo a classificação de Köppen, com temperatura média anual de $25^{\circ} \mathrm{C}$ e precipitação média anual entre 1600 à $1800 \mathrm{~mm}$.

A área de 216 ha possui sistema de Pivô Central, que permite irrigar 155 ha, restando então 61 ha que não são cobertos pela irrigação, a área em que o experimento foi conduzido é de 0,432 ha. A Figura 1 ilustra a concentração de chuvas durante o período experimental de outubro de 2019 a abril de 2020.

Figura 1 - Balanço hídrico no período de condução do experimento.

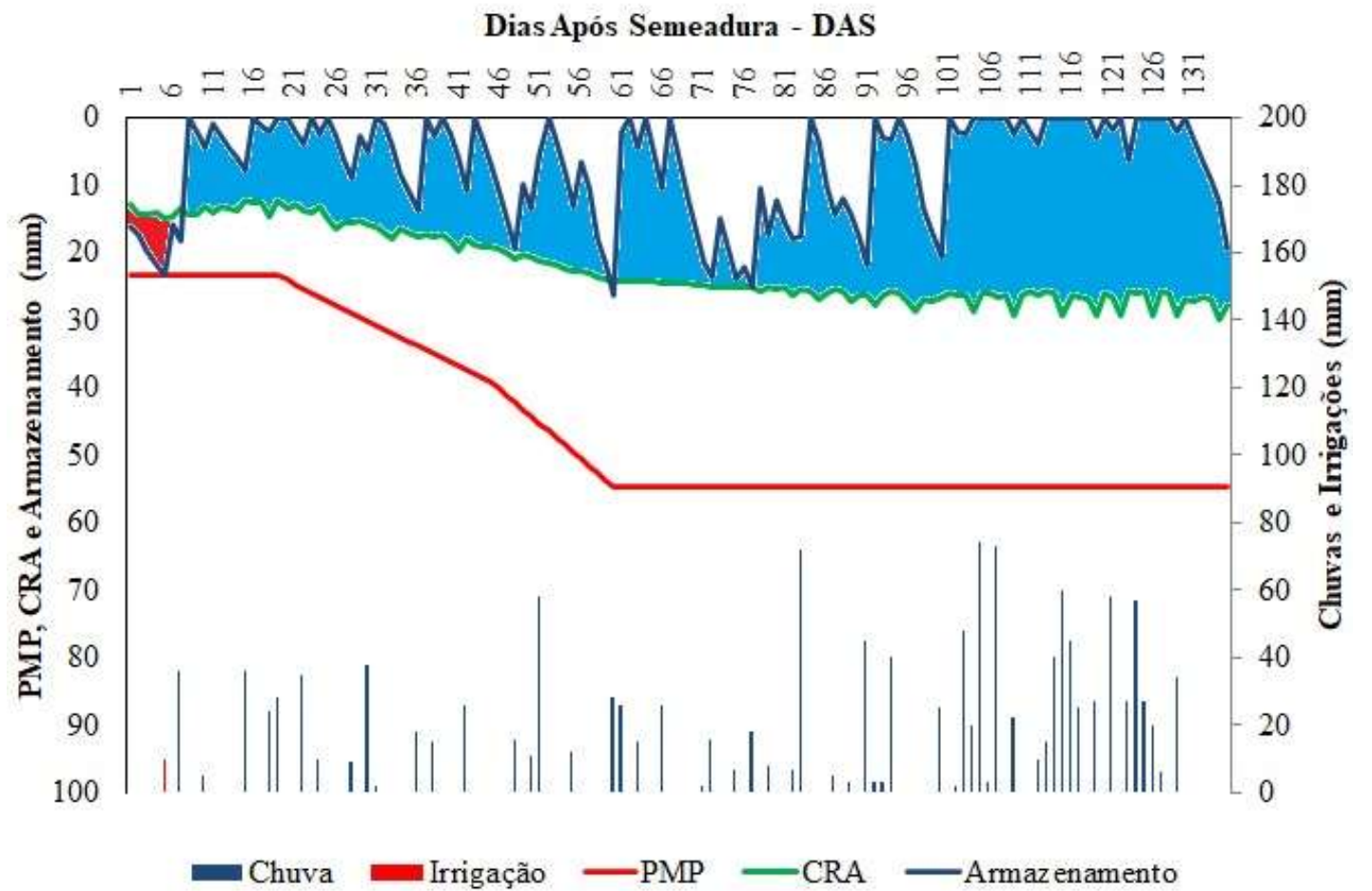

Fonte: Autores.

O solo no qual o experimento foi implantado, foi classificado segundo o Sistema Brasileiro de Classificação de solos como um Neossolo Quartzarênico (EMBRAPA 2018) e a Tabela 1 apresenta as análises físico-químicas da área experimental, mostrando a condição inicial do solo no momento da instalação do experimento. 
Research, Society and Development, v. 10, n. 1, e57610112243, 2021

(CC BY 4.0) | ISSN 2525-3409 | DOI: http://dx.doi.org/10.33448/rsd-v10i1.12243

Tabela1 - Análises Físico química do solo na área do experimento.

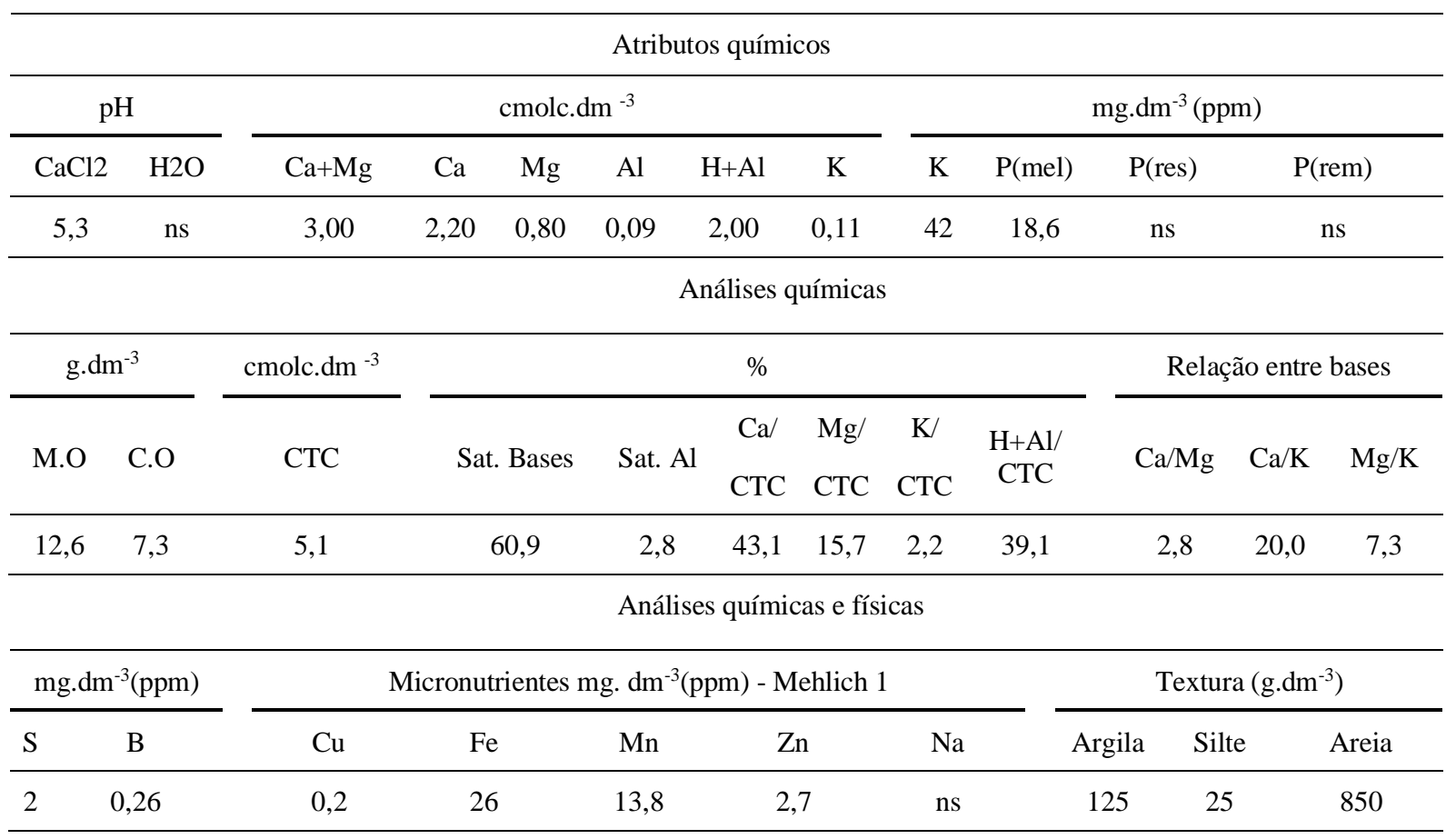

Fonte: Autores.

O delineamento utilizado foi o de blocos casualizados em esquema de faixas constituídas pelas cultivares DM 80 I79 IPRO, BONUS IPRO, Maracaí IPRO, DM 75I76, Foco IPRO e Aporé IPRO sendo apresentadas na Tabela 2, sob duas condições de água no solo (sequeiro e irrigado) com 4 repetições por tratamento, totalizando 48 parcelas.

Tabela 2 - Características das cultivares utilizadas no experimento.

\begin{tabular}{lcccc}
\hline Nome Comercial & Ciclo & Dias & Pop. Recomendada* & Sementes/metro \\
\hline DM80I79 & Intermediário & 122 & $180-220$ & 12 \\
BONUS & Intermediário & 122 & $250-300$ & 12 \\
MARACAI IPRO & Intermediário & 118 & $220-240$ & 12 \\
DM75I76 IPRO & Intermediário & 115 & $280-350$ & 12 \\
FOCO IPRO & Intermediário & 109 & $250-350$ & 14 \\
APORÉ IPRO & Intermediário & 115 & $300-360$ & 14 \\
\hline
\end{tabular}

*População Recomendada, expressa em mil plantas ha-1.

Fonte: Autores.

As sementes de soja foram tratadas com fungicida constituídos ativos Metalaxil -m, Tiabendazol, Fludioxonil (65 mL $\left.\mathrm{ha}^{-1}\right)$, inseticida com ingredientes ativos Thiametoxan $\left(200 \mathrm{~mL} 100 \mathrm{~g}\right.$ de semente $\left.{ }^{-1}\right)$ e nematicida com ingrediente ativo Abamectina $\left(70 \mathrm{~mL} \mathrm{ha}^{-1}\right)$. A colheita foi realizada individualmente para cada cultivar, no momento em que as mesmas atingiam a maturação fisiológica, as parcelas foram constituídas por duas linhas de semeadura de quatro metros cada, totalizando oito metros lineares.

O manejo da irrigação foi realizado via dados meteorológicos, onde a ETc foi obtida pelo produto da Evapotranspiração de Referência (ETo) e o Coeficiente de Cultivo (Kc). As estimativas de ETo foram obtidas pelo método Penman-Monteith-FAO, 
conforme Allen et al. (1998), utilizando dados de uma estação meteorológica automática do Instituto Nacional de Meteorologia (INMET), instalada próximo ao experimento. As irrigações eram realizadas a partir do balanço hídrico, apenas quando a cultura atingia o limite inferior da Capacidade Real de Água do solo (CRA). Os coeficientes de cultivo e a profundidade do sistema radicular de cada subperíodo foram definidos conforme recomendações Mantovani et al. (1997).

Os índices fenológicos da planta foram: altura de plantas (AP), medindo-se a distância vertical entre o solo e o final da haste principal, em cm; altura de inserção vagem (AV), medindo-se a distância vertical entre o solo e a primeira vagem, em cm; número de plantas (NP), com contagem do número total de plantas em um metro, adimensional; número de vagens por planta (NVP), adimensional; número de grãos por planta (NGP) e número de ramos (RA), adimensional; número de nós (NN), adimensional; massa de cem grãos (MCG), através da pesagem de cem grãos e produtividade de grãos (PROD), em kg ha-1 obtido com a pesagem dos grãos na parcela. As variáveis MCG e PROD foram determinadas por um amostrador eletrônico no momento da avaliação, obtiveram suas massas corrigidas para a umidade padrão de armazenagem de $13 \%$.

A metodologia de escrita deste estudo seguiu a recomendação de Pereira et. al (2018), e os dados foram avaliados estatisticamente e submetidos à análise de variância para as diferentes fontes, ao teste de comparação de médias Tukey a 5\% de probabilidade, utilizando-se o software estatístico SISVAR versão 4.3.

\section{Resultados e Discussão}

A análise de variância dos índices fenológicos da planta avaliados, são apresentados na Tabela 3 sendo eles número de plantas (NP), altura de plantas (AP), altura de inserção da primeira vagem (AV), número de nós da haste principal (NN), número de ramos (RA), número de vagens por planta (VP), número de grãos por planta (GP), massa de cem grãos (MC) e produtividade (PROD) da soja.

Tabela 3 - Análise de variância para número de plantas (NP), altura de plantas (AP), altura de inserção da primeira vagem (AV), número de nós da haste principal (NN), número de ramos (RA), número de vagens por planta (VP), número de grãos por planta (GP), massa de cem grãos (MC) e produtividade (PROD) da soja.

\begin{tabular}{|c|c|c|c|c|c|c|c|c|c|c|}
\hline Variação & GL & NP & $\mathrm{AP}$ & AV & $\mathrm{NN}$ & RA & VP & GP & MC & PROD \\
\hline Rep & 3 & $6,48 \mathrm{E}-1$ & $4,60 \mathrm{E}+1$ & $1,03 \mathrm{E}+0$ & $2,82 \mathrm{E}+0$ & $1,06 \mathrm{E}+0$ & $1,84 \mathrm{E}+2$ & $1,92 \mathrm{E}+3$ & $3,47 \mathrm{E}+1$ & $2,83 \mathrm{E}+5$ \\
\hline Irrig. (I) & 1 & $1,65 \mathrm{E}+0^{\mathrm{ns}}$ & $2,22 \mathrm{E}+2^{\mathrm{ns}}$ & $1,75 \mathrm{E}-1^{\mathrm{ns}}$ & $4,07 \mathrm{E}-1^{\mathrm{ns}}$ & $1,81 \mathrm{E}-3^{\mathrm{ns}}$ & $4,40 \mathrm{E}-1^{\mathrm{ns}}$ & $2,84 \mathrm{E}+0^{\mathrm{ns}}$ & $2,34 \mathrm{E}+1^{\mathrm{ns}}$ & $9,11 \mathrm{E}+5^{\mathrm{ns}}$ \\
\hline Res. (A) & 3 & $1,40 \mathrm{E}+0$ & $5,19 \mathrm{E}+1$ & $9,75 \mathrm{E}+0$ & $4,15 \mathrm{E}+0$ & $3,69 \mathrm{E}-1$ & $2,91 \mathrm{E}+2$ & $1,31 \mathrm{E}+3$ & $2,24 \mathrm{E}+1$ & $1,32 \mathrm{E}+5$ \\
\hline Cult. (C) & 5 & $1,93 \mathrm{E}+1^{* *}$ & $9,58 \mathrm{E}+2^{* * *}$ & $8,64 \mathrm{E}+1^{* *}$ & $5,91 \mathrm{E}+0^{* *}$ & $5,58 \mathrm{E}+0^{* * *}$ & $2,42 \mathrm{E}+3^{* *}$ & $4,18 \mathrm{E}+3^{\mathrm{ns}}$ & $3,09 \mathrm{E}+1^{\mathrm{ns}}$ & $8,32 \mathrm{E}+5^{* *}$ \\
\hline $\mathrm{I}^{*} \mathrm{C}$ & 5 & $9,37 \mathrm{E}-1^{\mathrm{ns}}$ & $6,44 \mathrm{E}+1^{*}$ & $8,29 \mathrm{E}+0^{\mathrm{ns}}$ & $6,11 \mathrm{E}-1^{\mathrm{ns}}$ & $8,75 \mathrm{E}-1^{\mathrm{ns}}$ & $3,91 \mathrm{E}+2^{\mathrm{ns}}$ & $4,90 \mathrm{E}+3^{*}$ & $3,16 \mathrm{E}+1^{\mathrm{ns}}$ & $5,97 \mathrm{E}+5^{*}$ \\
\hline Res. (B) & 30 & $5,44 \mathrm{E}-1$ & $1,90 \mathrm{E}+1$ & $9,43 \mathrm{E}+0$ & $1,09 \mathrm{E}+0$ & $6,17 \mathrm{E}-1$ & $3,36 \mathrm{E}+2$ & $2,06 \mathrm{E}+3$ & $2,68 \mathrm{E}+1$ & $1,80 \mathrm{E}+5$ \\
\hline Total & 47 & & & & & & & & & \\
\hline $\begin{array}{l}\text { CV (\%) } \\
\text { Parcela }\end{array}$ & & 14,35 & 7,83 & 20,70 & 9,76 & 15,15 & 16,98 & 16,03 & 24,44 & 6,14 \\
\hline $\begin{array}{c}\text { CV }(\%) \\
\text { Subparcela }\end{array}$ & & 8,94 & 4,73 & 20,36 & 5,00 & 19,58 & 18,25 & 20,12 & 26,77 & 7,14 \\
\hline
\end{tabular}

ns: não significativo $(\mathrm{P}>0,05)$; *: significativo $(\mathrm{P}<0,05)$; **: significativo $(\mathrm{P}<0,01)$; $\mathrm{CV}$ : coeficiente de variação; I: Condição de Sequeiro ou Irrigação; C: Cultivar; GL: Grau de Liberdade.

Fonte: Autores. 
Research, Society and Development, v. 10, n. 1, e57610112243, 2021

(CC BY 4.0) | ISSN 2525-3409 | DOI: http://dx.doi.org/10.33448/rsd-v10i1.12243

Os valores médios encontrados para os índices fenológicos estudados da planta de soja, são apresentados na Tabela 4 e 5.

Tabela 4 - Valores médios do número de plantas (NP), altura de plantas (AP), Altura de inserção da primeira vagem (AV), número de nós da haste principal $(\mathrm{NN})$ e número de ramos (RA) da soja.

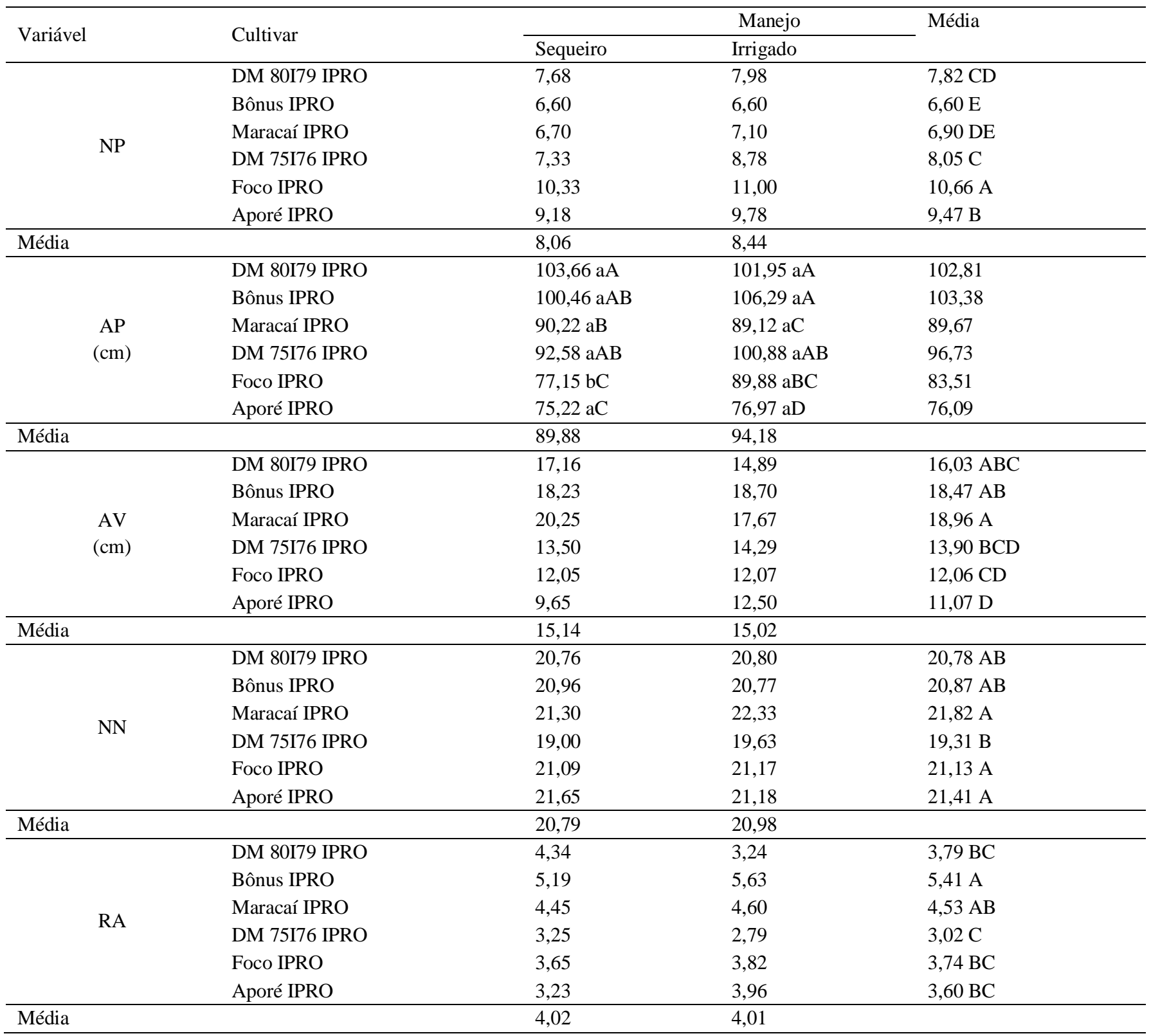

Médias seguidas por letras maiúsculas e minúsculas entre as linhas e colunas, respectivamente, diferem entre si pelo teste de Tukey (p $<0,05)$.

Fonte: Autores. 
Tabela 5 - Valores médios do número de vagens por planta (VP), número de grãos por planta (GP), massa de cem grãos (MC) e produtividade (PROD).

\begin{tabular}{|c|c|c|c|c|}
\hline \multirow{2}{*}{ Variável } & \multirow{2}{*}{ Cultivar } & \multicolumn{2}{|r|}{ Manejo } & \multirow[t]{2}{*}{ Média } \\
\hline & & Sequeiro & Irrigado & \\
\hline \multirow{6}{*}{ VP } & DM 80I79 IPRO & 93,94 & 83,30 & $88,62 \mathrm{BC}$ \\
\hline & Bônus IPRO & 123,75 & 132,86 & $128,31 \mathrm{~A}$ \\
\hline & Maracaí IPRO & 91,05 & 97,73 & $94,39 \mathrm{BC}$ \\
\hline & DM 75I76 IPRO & 93,21 & 71,04 & $82,13 \mathrm{C}$ \\
\hline & Foco IPRO & 94,88 & 95,09 & $94,99 \mathrm{BC}$ \\
\hline & Aporé IPRO & 106,62 & 122,27 & $114,44 \mathrm{AB}$ \\
\hline Média & & 100,57 & 100,38 & \\
\hline \multirow{6}{*}{ GP } & DM 80I79 IPRO & $202,03 \mathrm{aA}$ & $193,40 \mathrm{aAB}$ & 197,71 \\
\hline & Bônus IPRO & $248,64 \mathrm{aA}$ & $267,18 \mathrm{aA}$ & 257,91 \\
\hline & Maracaí IPRO & $220,65 \mathrm{aA}$ & $234,35 \mathrm{aAB}$ & 227,50 \\
\hline & DM 75I76 IPRO & $252,50 \mathrm{aA}$ & $171,67 \mathrm{bB}$ & 212,08 \\
\hline & Foco IPRO & $218,24 \mathrm{aA}$ & $207,75 \mathrm{aAB}$ & 213,00 \\
\hline & Aporé IPRO & $211,37 \mathrm{bA}$ & $282,00 \mathrm{aA}$ & 246,68 \\
\hline \multirow[t]{3}{*}{ Média } & & 225,57 & 226,06 & \\
\hline & DM 80I79 IPRO & $5133,64 \mathrm{bC}$ & $6152,12 \mathrm{aA}$ & 5642,88 \\
\hline & Bônus IPRO & $5700,39 \mathrm{aABC}$ & $6207,55 \mathrm{aA}$ & 5953,97 \\
\hline \multirow{4}{*}{$\begin{array}{c}\text { PROD } \\
\left(\mathrm{kg} \mathrm{ha}^{-1}\right)\end{array}$} & Maracaí IPRO & $5288,70 \mathrm{aBC}$ & $5863,84 \mathrm{aA}$ & 5576,27 \\
\hline & DM $75 I 76$ IPRO & $6056,47 \mathrm{aAB}$ & 5596,89 aA & 5826,68 \\
\hline & Foco IPRO & $6027,55 \mathrm{aAB}$ & $6268,68 \mathrm{aA}$ & 6148,11 \\
\hline & Aporé IPRO & $6548,10 \mathrm{aA}$ & $6318,95 \mathrm{aA}$ & 6433,53 \\
\hline Médias & & 5792,48 & 6068,01 & \\
\hline
\end{tabular}

Médias seguidas por letras maiúsculas e minúsculas entre as linhas e colunas, respectivamente, diferem entre si pelo teste de Tukey ( $\mathrm{p}<0,05)$. Fonte: Autores.

Para a variável número de plantas (NP), a cultivar Foco IPRO, obteve o maior resultado quando comparado com as demais, diferindo de todas, apresentando média de 10,66 plantas por metro linear, com incremento de 38,08 \% por metro linear quando comparada com a cultivar Bônus IPRO, que apresentou a menor média, 6,60 plantas por metro linear, não diferindo da cultivar Maracaí IPRO.

Já para número de ramos (RA), o maior valor foi encontrado na cultivar Bônus IPRO, com média de 5,41 ramos, não diferindo da cultivar Maracaí IPRO, e apresentando acréscimo de 44,17 \% quando comparada com a cultivar DM 75 I76 IPRO, esta, por sua vez, com o menor resultado, 3,02 ramos, não diferiu das cultivares Foco IPRO, Aporé IPRO e DM 80 I79.

Pode-se levar em consideração também que, relacionando as cultivares, o aumento da densidade de plantas e as práticas de manejo da cultura da soja, com o arranjo espacial das plantas pode influenciar significativamente a velocidade de fechamento das entre linhas, e principalmente as características como a produção de fitomassa, a arquitetura das plantas, a indulgências de doenças, o acamamento implicando diretamente na produtividade da cultura (Balbinot Junior, 2015). Em relação a alta densidade de plantas, verificamos que há estimulação na redução do diâmetro da haste da soja, influenciando também em características como, número de ramificações por planta, no número de vagens por planta e no número de grãos por planta (SOUZA, C. A. et al. 2010). 
A soja tolera uma ampla variação na população de plantas, alterando mais a sua morfologia que o rendimento de grãos, justificando assim os resultados apresentados, onde a cultivar com a menor população, demonstrou estatisticamente a maior quantidade de ramos por planta, devido a influência do espaçamento entre plantas. Esse fato, acontece devido ao arranjo afetar a competição intraespecífica e, dessa forma, a quantidade de recursos do ambiente, como água, luz e nutrientes disponíveis para cada planta.

Em relação à altura de plantas (AP), em condição de sequeiro, a cultivar DM 80179 IPRO, demonstrou a maior média de 103,66 cm, não diferindo das cultivares Bônus IPRO e DM75I76, obtendo um acréscimo na altura de 27,43\% quando comparada com a cultivar Aporé IPRO, com média de 75,22 cm, essa, não diferindo da cultivar da Foco IPRO. A altura da Planta é importante característica de crescimento que indica seu desenvolvimento. Esta característica é intimamente relacionada ao manejo imposto à lavoura. Desta forma, a identificação da variabilidade deste índice fenológico podem colaborar com os produtores na identificação de distorções que estão ocorrendo em campo de forma a possibilitar sua correção (Oliveira et al., 2018).

Já em condição de irrigação, a cultivar Bônus IPRO, obteve a maior altura, com média de 106,29 cm, não diferindo das cultivares DM 75 I76 IPRO e DM 80 I79 IPRO, e quando comparada com a cultivar Aporé IPRO, que apresentou a menor média, $76,97 \mathrm{~cm}$, apresenta $27,58 \%$ de incremento em sua altura.

Quando comparadas as duas condições, sequeiro e irrigado, a cultivar Foco IPRO apresenta diferenças estatísticas, onde em condição de sequeiro, apresentou medias de $77,15 \mathrm{~cm}$ de altura, já quando irrigada, obteve incremento de $14,16 \%$ alcançando média de $89,88 \mathrm{~cm}$ de altura de planta.

Como abordado por Larcher, (2006), há uma redução na altura de plantas submetidas ao estresse hídrico, devido a redução da turgescência, inibindo a fotossíntese e, consequentemente, o processo de crescimento durante o desenvolvimento. Ainda nesta linha, Petry (2000), Thomas e Costa (1994), mostram uma redução na altura das plantas quando em condições de défice hídrico, devido à diminuição do número de nós e comprimento de entrenós.

Para altura de inserção de primeira vagem (AV), a cultivar Maracaí IPRO, demonstrou a maior média, 18,96 cm, não diferindo das cultivares Bônus IPRO e DM 80 I79 IPRO, já a cultivar Aporé IPRO, apresentou o menor valor, com resultado médio de 11,07 cm, não diferindo das cultivares Foco IPRO e DM 75I76, tendo disparidade de 42,08 \% quando comparado com o maior resultado.

Fato que se relaciona diretamente com o aproveitamento de luz na parte inferior do dossel, ou seja, quanto mais luz atingir a camada inferior do dossel, mais baixo será o nó do primeiro legume e, consequentemente, a altura de inserção do primeiro legume (Zabot, 2009)

Em relação à número de nós na haste principal (NN), a cultivar Maracaí IPRO apresentou o maior número de nós na haste principal, com média de 21,82 nós e diferiu somente da cultivar DM 75I76, que apresentou a menor média, com 19,31 nós, tendo diferença de 11,50 \% quando comparado com o maior valor, não diferindo das cultivares DM 80I79 e Bônus IPRO.

Para número de vagens por planta (VP), a cultivar Bonûs IPRO apresentou a melhor média, com 128,31 vagens, porém não diferiu da cultivar Aporé IPRO, e houve um acréscimo de 35,99\%, quando comparada com a cultivar DM 75 I76 IPRO, que obteve a menor média, com 82,13 vagens por planta, não diferindo das cultivares Foco IPRO, Maracaí IPRO e DM 80179 IPRO.

Em sequeiro, observa-se a tendência de apresentar menor número de vagens por planta devido ao abortamento de flores e vagens promovidos pela deficiência hídrica nessa fase da cultura, em que a diminuição das vagens, se dá provavelmente em função do maior índice de abortamento de flores e vagens quando o défice hídrico ocorre no início dessas fases fenológicas. Resultados semelhantes foram encontrados por Silva et al. (2020).

Onde constatou que a produtividade da soja pode ser comprometida, pelo déficit hídrico que ocorre nos períodos mais críticos da cultura, implica afirmar que, em ocasiões como na semeadura, a emergência e no enchimento dos grãos, é necessário 
uma disponibilidade hídrica favorável, bem como condições climáticas. Isso contribui para uma alta em critérios de eficiência produtiva, e ao mesmo tempo minimiza perdas relacionadas a essa carência, tornando a irrigação fator primordial para o manejo da cultura. (Silva Et Al. 2020).

Em relação a número de grãos por planta (GP), considerando a interação entre as cultivares e as condições de sequeiro e irrigação, nota-se interação significativa em dois cultivares. Para a cultivar DM 75 I76 IPRO, em condição de sequeiro, foi obtida a média de 252,50 grãos por planta, porém em condição de irrigação, houve um decréscimo de 32,01 \% grãos, obtendo média de 171,67 grãos por planta.

Já para a cultivar Aporé IPRO em condição de sequeiro, foram encontrados resultados médios de 211,37 grãos por planta, porém, quando a mesma foi submetida a irrigação, obteve-se um acréscimo de 33,41\%, alcançando uma média de 282 grãos por planta.

Quando verificada a influência da irrigação entre as cultivares, a Aporé IPRO, apresentou a maior média, 282 grãos, diferindo somente da cultivar DM 75I76 IPRO que apresentou a menor média, 171,67 grãos por planta, apresentando uma disparidade de 39,12 \% e esta não diferiu das cultivares Maracaí IPRO, Foco IPRO e DM 80 I79 IPRO.

Como relatado por Kuss, 2006, plantas irrigadas somente em períodos críticos apresentam menores resultados do que plantas irrigadas durante todo ciclo, pelo fato de que a lâmina total aplicada em períodos críticos não tenha sido suficiente para garantir uma tão boa armazenagem de água no solo e consequente disponibilidade para as plantas. Aliando isso às diferentes características expressas pelas mais diferentes variedades, corrobora o resultado demonstrado acima, onde a variedade apresentou maior produção em condição de sequeiro, porém em outra variedade no mesmo local, o padrão não se manteve o mesmo.

Em relação a produtividade (PROD), a cultivar DM 80I79 IPRO apresentou interação significativa, quando submetida a condição de sequeiro e irrigação, onde em sequeiro, demonstrou média de $5133,64 \mathrm{~kg} \mathrm{ha}^{-1}$, já com irrigação, apresentou um acréscimo de16,55\%, alcançando média de 6152,12 $\mathrm{kg} \mathrm{ha}^{-1}$.

Em condição de sequeiro, quando comparada as médias entre as cultivares, a maior média foi encontrada na cultivar Aporé IPRO, com valor de 6548,10 kg ha-1, não diferindo das cultivares Bônus IPRO, DM 75I76 IPRO e Foco IPRO. Já o menor resultado foi obtido na cultivar DM 80I79 IPRO com média de 5133,64 $\mathrm{kg} \mathrm{ha}^{-1}$, apresentando diferença de 21,60 \%, quando comparado com o maior valor, e não diferindo das cultivares Bônus IPRO e Maracaí IPRO.

A produtividade da soja pode ser comprometida pelo déficit hídrico que ocorre nos períodos mais críticos da cultura, isso implica afirmar que em ocasiões como na semeadura, a emergência e no enchimento dos grãos é necessário uma disponibilidade hídrica favorável bem como condições climáticas, isso contribui para uma alta em critérios de eficiência produtiva, e ao mesmo tempo minimiza, perdas relacionadas a essa carência, tornando a irrigação fator primordial para o manejo da cultura. (SILVA et al. 2020).

Conforme apresentado durante todo o trabalho, a produtividade pode ser atribuída como reflexo direto dos demais fatores avaliados, sendo expresso, como resultado de suas influencias no produto final almejado.

\section{Conclusão}

Em solos arenosos, a variedade DM 80 I79 IPRO quando submetida a irrigação apresenta incremento na produtividade. Quando as cultivares foram submetidas à irrigação, todas expressaram incremento na produtividade, fato este comprovado pela não diferenciação estatística entre cultivares, conseguindo equilibrar seu potencial produtivo, variando somente devido a características de resistência a déficit hídrico, causando variabilidade produtiva entre as mesmas.

Sugere-se mais estudos nesta área, pois a estatística multivariada pode agregar muitos conhecimentos na cultura da soja e por isso, estudos com outros atributos como químicos e Influência de nematoides em cultivares de soja irrigadas, podem ajudar no melhor entendimento da produção da cultura. 
Research, Society and Development, v. 10, n. 1, e57610112243, 2021

(CC BY 4.0) | ISSN 2525-3409 | DOI: http://dx.doi.org/10.33448/rsd-v10i1.12243

\section{Agradecimentos}

À Universidade Federal do Maranhão (UFMA, Chapadinha, MA). À Universidade Federal do Mato Grosso do Sul (UFMS, Chapadão do Sul, MS). O desenvolvimento deste trabalho contou com apoio da Coordenação de Aperfeiçoamento de Pessoal de Nível Superior - Brasil (CAPES) - Código de Financiamento 001. E ao apoio do Conselho Nacional de Desenvolvimento Científico e Tecnológico (CNPq), pelas bolsas concedidas aos autores.

\section{Referências}

Balbinot Junior, A. A., Procopio, S. O., Debiasi, H., \& Franchini, J. C. (2015). Densidade de plantas na cultura da soja. Brasil: Embrapa Soja. <https://www.infoteca.cnptia.embrapa.br/infoteca/handle/doc/1028747>.

Companhia Nacional de Abastecimento - CONAB. (2020) Acompanhamento de safra brasileira: grãos, Safra $2019 / 20$ - N. 11 - Décimo primeiro levantamento. <https://www.conab.gov.br/info-agro/safras/graos/boletim-da-safra-de-graos>.

Empresa Brasileira de Pesquisa Agropecuária - EMBRAPA. (2018) Sistema Brasileiro de classificação de solos: EMBRAPA. ISBN 978-85-7035-817-2.

Flumignan, D. L., Almeida, A. C. S., \& Garcia, R. A. (2015). Necessidade de irrigação complementar da soja na região sul de Mato Grosso do Sul. Dourados: Embrapa Agropecuária Oeste, 8 p. (Embrapa Agropecuária Oeste. Circular técnica, 34). <https://ainfo.cnptia.embrapa.br/digital/bitstream/item/130258/1/CT201534.pdf>.

Gava, R. (2014). Os efeitos do estresse hídrico na cultura da soja (Glycine Max, (L.) Merrill.). 123 p. Tese (Doutorado em Irrigação e Drenagem) - Escola Superior de Agricultura Luiz de Queiroz, Universidade de São Paulo, Piracicaba, 2014. <https://www.teses.usp.br/teses/disponiveis/11/11143/tde-15092014113209/en.php>.

Kuss, R. C. R. (2006). Populações de plantas e estratégias de irrigação na cultura da soja. 81 p. <https://repositorio.ufsm.br/handle/1/7487>.

Larcher, W. (2006). Ecofisiologia Vegetal: RIMA, 531 p.

Mantovani, E. C., Costa, L. C., \& Leal, B. G. (1997). SISDA-Sistema de suporte a decisão agrícola. In Congresso de Informática Aplicada à Agropecuária e Agroindústria (Vol. 1). <http://www.bdpa.cnptia.embrapa.br/consulta>.

Oliveira, J. T., Passos, M., Roque, C. G., Baio, F. H. R., Kamimura, K. M., Ribeiro, I. S., \& Teodoro, P. E. (2018). Space variability of phenological indicators of common bean crop. Bioscience Journal, 34 (2). https://doi.org/10.14393/BJ-v34n2a2018-39659.

Pereira, A. S., Shitsuka, D. M., Parreira, F. J., \& Shitsuka, R. (2018). Metodologia da pesquisa científica. [e-book]. Santa Maria. Ed. UAB/NTE/UFSM.https://repositorio.ufsm.br/bitstream/handle/1/15824/Lic_Computacao_Metodologia-Pesquisa-Cientifica.pdf?sequence=1..

Petry, M. T. (2000). Interação solo-planta e disponibilidade de água no solo às plantas de sorgo e soja. 127 f. Dissertação (Mestrado em Agronomia) Universidade Federal de Santa Maria, Santa Maria, 2000. <https://repositorio.ufsm.br/handle/1/25>.

Rodrigues, L. N. (2020) Quantidade de água utilizada na agricultura irrigada: certezas e incertezas nas estimativas. Embrapa Cerrados-Artigo em periódico indexado (ALICE). <https://www.alice.cnptia.embrapa.br/handle/doc/1123349>.

Silva, L. P., Battisti, R., Knapp, F. M., Santos, T. G., \& Junior, J. A. (2020). Estimativa da produtividade de soja usando irrigação na época das chuvas no bioma Cerrado. Agrometeoros, 28.Souza, C. A. et al. Relação entre densidade de plantas e genótipos de soja Roundup ReadyTM. Planta Daninha, 28(4), 887-896, 2010. http://dx.doi.org/10.31062/agrom.v28.e026702.

Thomas, A. L., \& Costa, J. A. (1994). Influência do défice hídrico sobre o desenvolvimento e rendimento da soja. Pesquisa Agropecuária Brasileira, Brasília, 29(9), 1389- 1396. <https://www.alice.cnptia.embrapa.br/handle/doc/105164>.

Venancio, L. P., Cunha, F. F. D., Mantovani, E. C., Sediyama, G. C., Eugenio, F. C., \& Aleman, C. C. (2019). Penman-Monteith com dados faltantes e Hargreaves-Samani para estimativa da ETo no estado do Espírito Santo, Brasil. Revista Brasileira de Engenharia Agrícola e Ambiental, 23 (3), 153-159. http://dx.doi.org/10.1590/1807-1929/agriambi.v23n3p153-159.

Zabot, L. (2009). Caracterização agronômica de cultivares transgênicas de soja cultivadas no Rio Grande do Sul. 280 f. Teses (Doutorado em Agronomia) Universidade Federal de Santa Maria, Santa Maria. <https://repositorio.ufsm.br/handle/1/3186>. 